Koopman, L., Donselaar, L.C.G., Rademakers, J.J., Hendriks, M. A prenotification letter increased initial response, whereas sender did not affect response rates. Journal of Clinical

\begin{tabular}{|l|l|}
$\begin{array}{l}\text { Postprint } \\
\text { Version }\end{array}$ & 1.0 \\
\hline Journal website & http://www.jclinepi.com/article/S0895-4356(12)00308-3/abstract \\
\hline Pubmed link & $\underline{\text { http://www.ncbi.nlm.nih.gov/pubmed/23347856 }}$ \\
\hline DOI & $10.1016 /$ j.jclinepi.2012.09.012. \\
\hline
\end{tabular}

This is a NIVEL certified Post Print, more info at http://www.nivel.eu

\title{
A prenotification letter increased initial response, whereas sender did not affect response rates
}

\author{
LAURA KOOPMAN, LeA (C) G. DONSElAAR, JANY J. RADEMAKERS, MiCHELle HENDRIKS
}

\begin{abstract}
Objective

To find ways to improve response rates of medical and health surveys. We investigated whether a prenotification letter instead of a second reminder and varying senders of the questionnaires would affect response rates.

Study Design and Setting

We present the results of two studies. In the first study, four groups were compared that either received a prenotification letter (group 1 and 2) or a second reminder letter (group 3 and 4); received the questionnaire from either a research institute (group 1 and 3) or a health insurance company (HIC; group 2 and 4). In the second study, we compared two groups that received the questionnaire sent by either a HIC or a hospital. Response rates, response speed, respondent characteristics, item nonresponse, and mean scores on quality aspects and global ratings were compared.

Results

Response rates did not differ significantly between groups. Prenotification groups returned their questionnaires faster. No other significant differences were found for response speed, respondent characteristics, item nonresponse, or mean scores.

Conclusion
\end{abstract}

A prenotification letter does only increase initial response speed and does not increase total response rates. A prenotification letter should be considered when quick response is desirable. Varying senders had no effect on response rates.

[Box 1] 
Koopman, L., Donselaar, L.C.G., Rademakers, J.J., Hendriks, M. A prenotification letter increased initial response, whereas sender did not affect response rates. Journal of Clinical Epidemiology: 2013, 66(3), 340-348

\section{INTRODUCTION}

Paper questionnaires are widely used to collect data for medical and health services researches [1], [2], [3], [4], [5] and [6]. However, much variation in response rates has been observed. A systematic review of American studies showed a mean response rate of $60 \%$ in paper questionnaires, with a standard deviation of $21 \%$ [1]. In the Netherlands, Zuidgeest et al. [7] found an average response rate of 55\%

(range: 20-79\%) for studies using a patient experience questionnaire, the Consumer Quality Index. Nonresponse reduces the effective sample size and can introduce bias. Finding ways to increase or maintain response rates for paper questionnaires may, therefore, improve the quality of the research.

A lot of research has been done on factors that may influence response rates. For instance, a review by Edwards et al. [2], in which he investigated 481 trials on paper questionnaires, showed that response rates increase considerably when using monetary incentives, a teaser on the envelope or a more interesting questionnaire topic. Other factors that may increase response rates are using a prenotification, follow-up contact, shorter questionnaires, providing a second copy of the questionnaire at follow-up, mentioning an obligation to respond, university sponsorship, personalized questionnaires, and an assurance of confidentiality. Response rates reduce when the questionnaire includes questions of sensitive nature. A review and meta-analysis of Nakash et al. [8] also showed that intensive reminder systems, shorter questionnaires, and incentives may improve response rates.

An important method that describes procedures to increase response rates is the "total design method (TDM)" developed by Dillman [9] and [10]. The TDM is "the identification of each aspect of the survey process (even the minute ones) that may affect response quantity or quality and shaping them in a way that will encourage good response." In other words, Dillman argues that each aspect of a questionnaire study may influence the willingness to respond on an invitation to fill out a questionnaire. Important features of the TDM are the design of the questionnaire, the cover letter, return envelope, mail out date, and follow-up mailings.

There are also studies that combined some of the above-mentioned factors, to investigate whether it might result in higher response rates than using just one of these factors. However, results of such studies are inconclusive [11], [12], [13], [14], [15] and [16]. For instance, Slijkhuis et al. [16] showed that using a prenotification and follow-up contact increased response rates compared with using only follow-up contact, whereas Hammink et al. [13] combined prenotification and follow-up without any positive result. Slijkhuis et al. [16] also showed that sending a second paper questionnaire in combination with a prenotification did not influence response rates. Moreover, Hart et al. [14] showed that personalized prenotification with an emailed survey did not have a significant positive effect on response rates. Beebe et al. [11] investigated the impact of manipulating questionnaire length (two- vs. four page) and prenotification type (letter or postcard). Results showed that response rates did not vary according to questionnaire length or prenotification type. Kelly et al. [15] tested the following two factors, a money incentive (3 or 5\$) and length of the questionnaire (short or long). Combining these factors did not result in higher response rates. Draisma and Smit [12] investigated whether a personalized introduction letter and a final reminder by telephone with the possibility for a 
Koopman, L., Donselaar, L.C.G., Rademakers, J.J., Hendriks, M. A prenotification letter increased initial response, whereas sender did not affect response rates. Journal of Clinical Epidemiology: 2013, 66(3), 340-348

telephonic interview had an effect on response. It turned out that the telephonic contact increased response substantially from 23\% to 51\%.

In the Netherlands, questionnaires are increasingly used to measure quality of care from a consumers' perspective. The Dutch standard (since 2006) to measure quality of care from a consumers' perspective is the Consumer Quality Index (CQI) [17], [18] and [19]. One of the first developed CQI instruments is the CQI Health plan, which has been administered yearly from 2005 onward [17]. Response rates for the CQI Health plan are declining over the years, response rates of 45\%, 39\%, 34\%,

$31 \%$, 32\%, and 33\% were found, respectively for 2005-2010 [20], [21], [22], [23], [24] and [25]. This trend is also seen for other CQI surveys. These trends are in line with other literature that shows that response rates in health services research have been declining over the past few decades [11]. To ensure a minimum number of respondents, the sample size for the CQI Health plan has been increased over the years. It is however not possible to continue increasing the sample size. Therefore we have decided to investigate factors that may increase response rates.

The CQI consists of a series of questionnaires and guidelines on how to collect consumers' experiences with health care. The standard CQI data collection method, based on the TDM [9] and [10], is first to send out a paper questionnaire with cover letter at week 0 , followed by a thank you/reminder postcard at week 1 , a reminder letter including a second paper questionnaire at week 4 , and usually a third reminder letter at week 6. Mostly the cover letters are sent on behalf of the health insurance company (HIC) because databases of insurance companies are used to select participants.

We decided to investigate two factors that might affect the response rate as mentioned by Edwards et al. [2]. First, whether a prenotification letter instead of a second reminder improves response rates or response speed was investigated. Prenotification may work because it underscores the legitimacy of the survey, takes away suspicion, communicates the value of the survey, and evokes the principles of social exchange [26]. Second, whether the sender (hospital, HIC, or research institute [RI]) of a cover letter influence response rates was investigated. Research showed that consumers might be more willing to respond when senders are more familiar or when one feels affection for them [2]. The two factors were studied using the results of two CQI studies that were originally set up independent of each other. In a study on consumer experiences with their health plan (CQI health plan), we investigated whether prenotification and varying senders (either RI or HIC) had an effect on response rates and response speed (study 1 ). In a study on consumer experiences with a hospital admission (CQI Hospital admission), we again investigated whether the sender had an effect on response rates and response speed looking at another type of sender (either HIC or hospital; study 2). Varying sending scheme and type of sender might not only influence the response rate but it might also be that different groups of people respond or that some of the respondents fill in the questionnaires differently. Therefore, in both studies, we examined whether respondent characteristics, item nonresponse, and mean scores on quality aspects and global ratings differed between the research conditions. 
Koopman, L., Donselaar, L.C.G., Rademakers, J.J., Hendriks, M. A prenotification letter increased initial response, whereas sender did not affect response rates. Journal of Clinical Epidemiology: 2013, 66(3), 340-348

\section{METHODS}

For this article, we used the results of two separate CQI studies. A study on consumer experiences with their health plan (CQI health plan) and a study on consumer experiences with their hospital admission (CQI hospital admission).

\subsection{CQI health plan}

Data were collected as part of a bigger study in May 2009. Inclusion criteria were: 18 years or older and at least for 12 months insured with the same health plan. In total, 800 insurers were randomly selected from the database of one Dutch health plan. Respondents were asked to fill out a short version of the CQI Health plan questionnaire measuring consumer experiences with their health plan in the past 12 months. The questionnaire consisted of 61 items in total (14 pages); 49 items were on experiences with their health plan and 1 asked for a global rating. Eleven of these items are summarized in three quality aspects (health plan information, reimbursement of claims, conduct of employees). These quality aspects were determined with factor analyses when the questionnaire was developed [23]. The total sample was equally divided into four groups. Group 1 and 2 received a prenotification letter from either the RI (group 1) or the HIC (group 2). Group 3 and 4 immediately received the questionnaire accompanied by a cover letter sent by either the RI (group 3) or the HIC (group 4) and received a second reminder. In Table 1, we show the survey methods of the CQI health plan in detail.

\section{[TABLE 1]}

\subsection{CQI hospital admission}

Data were collected in September/October 2009. Inclusion criteria: patients had to be 18 years or older, admitted to a hospital for at least $24 \mathrm{~h}$, with discharge date in May or June 2009. In total, 225 hospital patients were selected from the database of one Dutch hospital. Respondents were asked to fill out the CQI Hospital Admission measuring their experiences with their recent hospital admission. The questionnaire consisted of 91 items in total (11 pages); 75 items were on experiences with their hospital and 4 on global ratings. Fifty-five of these items are summarized in 13 quality aspects (accessibility, admission conversation, admission to hospital ward, communication nurses, communication physician, contradicting information health care staff/provider, hospital room and stay, own contribution, explanation of treatment, pain procedures, communication with medication, feeling of safety, and information on discharge). These quality aspects were determined with factor analyses when the questionnaire was developed [27].

The sample was divided into two groups, group A received a cover letter on behalf of the HIC ( $\mathrm{n}=112)$, whereas group B received a cover letter on behalf of the hospital $(\mathrm{n}=113)$. In Table 1, we show the survey methods of the CQI Hospital admission in detail.

\subsubsection{Data analysis}

Data collected with the CQI Health plan were analyzed separately from the CQI Hospital admission data. CQI Health plan data were first grouped and analyzed according to the sending method, that is receiving a prenotification (group 1 and 2) or a second reminder (group 3 and 4); and according to the sender, either the RI 
Koopman, L., Donselaar, L.C.G., Rademakers, J.J., Hendriks, M. A prenotification letter increased initial response, whereas sender did not affect response rates. Journal of Clinical Epidemiology: 2013, 66(3), 340-348

(group 1 and 3) or the HIC (group 2 and 4). Second, we looked at combined effects between the sending methods, that is groups 1-4 were compared directly.

The primary outcome measure was the final response defined as total response rate at the end of the data collection period and pattern of response speed. To calculate final response rates, we started with the sampled number of patients. Then deceased patients, patients younger than 18 years old, patients for whom the questionnaire was returned because of a wrong address and nonhospitalized patients (CQI Hospital admission only) were excluded from the study. This resulted in a net number of patients that was sent a questionnaire. Subsequently, respondents who did not return the questionnaire, filled out too few questions ( $<50 \%$ of the obligatory questions) or did not fill out the questionnaire by themselves were subtracted from the net number of sent questionnaires to determine final response rate. Final response rates were compared using two-way analysis of variance (ANOVA) for study 1. Using two-way ANOVA, we were also able to test for interaction between sending method and sender. For study 2, $\mathrm{X} 2$ tests were used to compare final response rates. Differences in response speed between groups were tested using Wilcoxon Mann-Whitney test (when two groups were compared) or Kruskall-Wallis test (when four groups were compared). Response speed was calculated in days starting from the day the questionnaires were send.

Secondary outcome measures were respondent characteristics, item nonresponse, total missing responses, and results on quality aspects and global rating. Respondent characteristics were described and differences were tested using $\mathrm{X} 2$ tests. Item nonresponse was determined by calculating nonresponse percentages. We only compared item nonresponse for those items for which nonresponse exceeded 5\%. We used this cutoff criteria of $5 \%$ because that was also used in the construction phase of the instrument as a check whether respondents understood the question [23], [27] and [28]. Differences and confidence intervals (CIs) for nonresponse between groups were determined. In addition, we calculated overall missing responses for each group for all obligatory questions (study 1 had 39 obligatory questions; study 2 had 74 obligatory questions). Overall mean scores on quality aspects and global ratings were calculated; differences between groups were calculated and tested using ANOVA, while adjusting for age, sex, health status, and education.

\section{RESULTS}

\subsection{CQI health plan}

\subsubsection{Response rates}

Of the 800 selected insurees, 170 consumers turned out to be younger than 18 years; 1 consumer was deceased, and for 2 selected consumers the address was incorrect. Consequently, 627 selected insurees were eligible to participate. Of these 627, 191 (30\%) completed and returned the questionnaire.

The combined response rate of the prenotification groups was $29 \%$, which did not differ significantly from the combined response rate for the groups that received a second reminder ( $32 \% ; \mathrm{F}=0.34, \mathrm{P}=0.56)$. When comparing response rates of the groups that were sent a letter from either an RI (30\%) or an HIC (31\%), there was 
Koopman, L., Donselaar, L.C.G., Rademakers, J.J., Hendriks, M. A prenotification letter increased initial response, whereas sender did not affect response rates. Journal of Clinical Epidemiology: 2013, 66(3), 340-348

only a small and nonsignificant difference between both groups $(\mathrm{F}=0.45, \mathrm{P}=0.68)$. The interaction effect between sending method and sender was also not significant ( $\mathrm{F}$ $=0.17, \mathrm{P}=0.68$ ) The response rates for groups $1-4$ were $28 \%, 30 \%, 33 \%$, and $31 \%$, respectively.

\subsubsection{Respondent characteristics}

In Table 2, the characteristics of the respondents of the CQI Health plan are shown. There were only small and nonsignificant differences found for age, sex, health status, and education between the four groups. Highest response was seen for respondents between 55 and 65 years old, $56 \%$ of the respondents were female, and $51 \%$ of the respondents rated their health status as good.

\section{[TABLE 2]}

We also compared the characteristics according to sending method or sender; however, all differences were not significant (data not shown).

\subsubsection{Response speed and pattern}

We also compared the response speed and patterns between the sending methods. For both groups, there was one returned questionnaire for which the response date was not marked. Table 3 shows the response in blocks of 7 days corresponding to the timing of the reminders. In the first 7 days after sending the questionnaire, response was higher for the prenotification groups (9\% vs. 0\%). However, after 14 days, response was higher for the groups that received a second reminder ( $20 \%$ vs. $14 \%$ ). Overall, the mean response time for the prenotification group was 16.5 days and for the second reminder group it was 19.3 days. In Fig. 1, the response speed of the prenotification vs. second reminder groups are shown in days. There was a clear and significant difference in response speed between the pre-notification and second reminder groups $(\mathrm{z}=-2.287, \mathrm{P}=0.02)$. The pre-notification groups responded faster and more gradually, whereas for the groups that received a second reminder we saw a peak in the response around 13 days after sending the first questionnaire and another small peak around 33 days.

\section{[TABLE 3 AND FIGURE 1]}

In Fig. 2, the response speed of the RI vs. HIC groups are shown in days. When the speed and patterns of the RI groups and HIC groups were compared, we saw that in the first 14 days after sending the questionnaire, response was almost equal for both groups (RI 16\% vs. HIC 17\%); after 4 weeks, response was somewhat higher for the HIC groups (27\% vs. 23\%; Table 3). However, in the last 3 weeks, the response for the RI groups was slightly higher, which resulted in equal response rates at the end of the data collection period. Overall, the mean response time for the RI group was 19.5 days and for the HIC group it was 16.5 days. Response speed was very similar for both sender (RI and HIC) groups $(\mathrm{z}=1.214, \mathrm{P}=0.22)$ (Fig. 2$)$. 
Koopman, L., Donselaar, L.C.G., Rademakers, J.J., Hendriks, M. A prenotification letter increased initial response, whereas sender did not affect response rates. Journal of Clinical Epidemiology: 2013, 66(3), 340-348

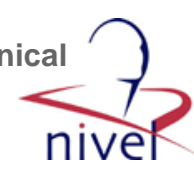

\section{[FIGURE 2]}

When response speed for all four groups was compared, we saw that for group 2 (prenotification and HIC) mean response speed was highest (15.9 days), whereas for group 3 (second reminder and RI) mean response speed was lowest (21.6 days). Overall, response speed showed a small significant difference between the four groups $(\mathrm{F}=3.11 ; \mathrm{P}=0.03)$. Response speed of each group separately showed a higher association with sending schemes than with sender (data not shown).

\subsubsection{Quality of data}

We also compared item nonresponse according to sending method and sender. We found seven items for which nonresponse exceeded 5\% nonresponse. For only one item (question 3, "Which basic insurance package do you have?"), nonresponse differed significantly between the prenotification groups (4\%) and the second reminder groups (15\%; difference 11\%, 99\% CI: 0-22\%). Overall proportions of missing responses for each group were $10 \%$. There were no significant differences in item nonresponse between the two sender groups or in overall missing responses between all four groups.

There were small but nonsignificant differences on the mean scores for the quality aspects and global rating between the prenotification groups and the second reminder groups, between the sender groups (RI vs. HIC), and between all four groups directly (all F's < 2.17), all P-values > 0.05). The biggest differences between groups were found for the global rating, the mean score varied between 7.8 (standard deviation [SD]: 1.46) for group 1, 8.4 (SD: 1.07) for group 2, 8.2 (SD: 1.24) for group 3, and 8.3 (SD: 1.28$)$ for group $4(\mathrm{~F}=1.33, \mathrm{P}=0.27)$.

\subsection{CQI hospital admission}

\subsubsection{Response rates}

Of the 225 selected hospital patients, one patient had deceased, while another had not been hospitalized. Consequently, 223 patients were eligible to participate. Of these 223, 110 (49\%) completed and returned the questionnaire. No significant differences were found in response rates between group A, which received a cover letter on behalf of the HIC, and group B, which received a cover letter on behalf of the hospital ( $\mathrm{X} 2[1]=0.0406 ; \mathrm{P}=0.84)$.

\subsubsection{Respondent characteristics}

In Table 4, the characteristics of the respondents of the CQI Hospital admission are shown. Only small significant differences were found for age, sex, health status, and education between the two hospital admission groups. Highest response was seen for respondents of 65 years and older, about half of the respondents were female (54\%), rated their health status as good (50\%), and finished at least high school (57\%). 
Koopman, L., Donselaar, L.C.G., Rademakers, J.J., Hendriks, M. A prenotification letter increased initial response, whereas sender did not affect response rates. Journal of Clinical Epidemiology: 2013, 66(3), 340-348

\section{[TABLE 4]}

\subsubsection{Response speed and pattern}

Response patterns and speed were compared between group A (HIC) and B (hospital). Table 5 shows response in blocks of 7 days corresponding to the timing of the reminders. The table shows that response in the group $B$ is slightly faster than in the group A; however, group A catches up after 35 days. Overall, the mean response time for group A was 28.1 days and for group B was 23.7 days. In Fig. 3, the response speed of group $A$ and $B$ are shown in days. As is shown in this figure, response speed patterns are quite similar $(\mathrm{z}=1.128, \mathrm{P}=0.26)$.

\section{[TABLE 5 AND FIGURE 3]}

\subsubsection{Quality of data}

For 37 items, nonresponse exceeded 5\%. There was only one question (q1 "In the past 12 months have you been admitted to hospital X") for which item nonresponse differed significantly between both groups, difference 28\% (group A 26\%; group B 54\%) and 99\% CI: 5-51\%. Overall proportions of missing responses were $8 \%$ for group $\mathrm{A}$ and $\mathrm{B}$, this difference was not significant. There were small but nonsignificant differences between the two groups on mean scores of quality aspects and global ratings. The biggest difference was found for the global rating of nurses, for group A the mean score was 9.3 (SD: 1.10) and for group B 8.9 (SD: 1.20; F: 1.15; $\mathrm{P}=0.28$ ).

\section{DISCUSSION}

In this article, we investigated whether using a prenotification or varying sender affects response rates, (patterns of) response speed, respondent characteristics, item nonresponse, and mean scores on quality aspects and global ratings. We used the results of two surveys. In the first study, four groups with varying sending methods and different senders were compared, whereas in the second study two groups with different senders were compared. Response rates did not differ significantly according to sending method (i.e., study 1) or sender (i.e., study 1 and 2). Response speed (patterns) differed significantly between prenotification and second reminder groups; prenotification groups returned their questionnaires faster. Response speed (patterns) did not differ significantly according to the sender (i.e., study 1 and 2) or a combination of sender and sending method (i.e., study 1 ). We did not find relevant differences on item nonresponse and mean scores on quality aspects and global ratings between groups that could be attributed to sending method (i.e., study 1 ) or sender (i.e., study 1 and 2).

Respondent characteristics did not differ significantly among the study groups in the two studies. This means that the sending methods and senders did not attract different respondents. Consequently, population differences did not have an effect on our study.

Although the differences in response rates among the four groups in study 1 were not significant, there was, however, a small trend that the two groups that did not receive a prenotification but instead a second reminder had a higher response rate (32\% vs. 
29\%). The reason for this higher response rate might be the second reminder that included a letter and a second copy of the questionnaire, which the prenotification groups did not receive. These results are in line with the study of Hammink et al. [13] in which prenotification alone also resulted in slightly lower response rates. They also showed that combining prenotification and a reminder did not further increase response rates compared with only a reminder.

On the other hand, initial response speed was significantly higher for the prenotification groups. This result is in line with a study by Slijkhuis et al. [16], which also showed that prenotification leads to a higher initial response. A higher response speed implies that fewer reminders (with new questionnaires) have to be sent, which may consequently result in lower costs.

Our studies did not show any differences in response rates according to sender. A possible explanation is that our study populations were not more familiar or felt a more personal bond for one of our senders as hypothesized. The current senders were directors or other members of the directory or advisory board from either a hospital, an HIC, or an RI. Respondents might not feel any affection for such people. It might be that other persons, for instance their most frequently visited physician, might raise more familiar feelings that may result in higher response rates. Future research should investigate which sender might improve response rates.

Both studies did not show any differences in item nonresponse or scores on quality aspects and global ratings. From this, we can conclude that sending methods or sender did not have an influence on the way the respondents filled out the questionnaire.

A few elements of our study may limit the generalizability of our findings. The number of respondents in our analyses were quite low, especially in the second study. Because of the low number of respondents in both studies and the small differences in response rate and speed between treatment groups, it was more difficult to obtain statistically significant results. Moreover, with a low number of respondents, there is a higher risk that the results might be influenced by extremely high or low scores on quality aspects or global ratings of some respondents.

However, despite the low number of respondents, both studies showed similar results. We do, therefore, not believe that more respondents would have changed our results radically.

The sending scheme of the prenotification groups (receiving a thank you/reminder postcard 2 weeks after the questionnaire) was a little different from that of the second reminder groups (receiving a thank you/reminder postcard 1 week after the questionnaire) in the first study. The variance in sending schemes might have influenced the response rates. However, the response peaks did not exactly follow a reminder. It is, therefore, more likely that sending either a prenotification or a second reminder were of greater influence on the response rates.

In a future study, it would be interesting to investigate whether the effect of sending a thank you postcard at different time points influences response rates. Moreover, it would also be interesting to have an additional study group that receives both a prenotification and a second reminder.

In conclusion, increasing response rates in patient surveys remains a challenge. A prenotification letter increases only the initial response speed and not the total response rates. It, therefore, has added value only when reducing costs of data collection or when a quick response is desirable. Varying sender did not affect 
Koopman, L., Donselaar, L.C.G., Rademakers, J.J., Hendriks, M. A prenotification letter increased initial response, whereas sender did not affect response rates. Journal of Clinical Epidemiology: 2013, 66(3), 340-348

response rates in our study. More research is needed to investigate whether a more familiar sender might improve response rates.

\section{ACKNOWLEDGMENT}

CZ (Dutch Health Insurance Company) financed the data-collection with the CQI Health plan. Stichting Miletus (Collaboration of Health Insurance Companies to measure Patients' experiences with health care) financed the data-collection with the CQI Hospital Admission. We would like to thank both CZ and Stichting Miletus for providing the data and thank the Dutch Center for Consumer Experiences in Health Care for financing the data-analyses.

\section{REFERENCES}

[1] D.A. Asch, M.K. Jedrziewski, N.A. Christakis. Response rates to mail surveys published in medical journals. J Clin Epidemiol, 50 (1997), pp. 1129-1136

[2] P.J. Edwards, I. Roberts, M.J. Clarke, C. Diguiseppi, R. Wentz, I. Kwan et al.Methods to increase response to postal and electronic questionnaires. Cochrane Database Syst Rev, 3 (2009), p. MR000008

[3] P. Leece, M. Bhandari, S. Sprague, M.F. Swiontkowski, E.H. Schemitsch, P. Tornetta et al. Internet versus mailed questionnaires: a controlled comparison (2). J Med Internet Res, 6 (4) (2004), p. e39

[4] M.M. van Gelder, R.W. Bretveld, N. Roeleveld. Web-based questionnaires: the future in epidemiology? Am J Epidemiol, 172 (2010), pp. 1292-1298

[5] J.B. VanGeest, T.P. Johnson, V.L. Welch. Methodologies for improving response rates in surveys of physicians: a systematic review. Eval Health Prof, 30 (4) (2007), pp. 303-321

[6] M. Wenemark, A. Vernby, A.L. Norberg. Can incentives undermine intrinsic motivation to participate in epidemiologic surveys? Eur J Epidemiol, 25 (4) (2010), pp. 231-235

[7] M. Zuidgeest, D. de Boer, M. Hendriks, J. Rademakers. Different methods of data collection in CQI research: an overview of the response and representativeness of respondents. Tijdschrift voor Gezondheidswetenschappen, 86 (8) (2008), pp. 455-462

[8] R.A. Nakash, J.L. Hutton, E.C. Jorstad-Stein, S. Gates, S.E. Lamb. Maximising response to postal questionnaires-a systematic review of randomised trials in health research. BMC Med Res Methodol, 6 (2006), p. 5

[9] D.A. Dillman. Mail and telephone surveys. The total design method. John Wiley \& Sons, Inc., New York, NY (1978)

[10] D.A. Dillman. Mail and Internet surveys: the tailored design method. Wiley, New York, NY (2000)

[11] T.J. Beebe, E. Rey, J.Y. Ziegenfuss, S. Jenkins, K. Lackore, N.J. Talley et al. Shortening a survey and using alternative forms of prenotification: impact on response rate and quality. BMC Med Res Methodol, 10 (2010), p. 50

[12] S. Draisma, J.H. Smit. Responsverhogende maatregelen voor de Consumer Quality Index [Measures to increase response rates using Consumer Quality Index Surveys] GGZ inGeest, Amsterdam, The Netherlands (2010)

[13] A. Hammink, P. Giesen, M. Wensing. Pre-notification did not increase response rate in addition to follow-up: a randomized trial. J Clin Epidemiol, 63 (2010), pp. 1276-1278

[14] A.M. Hart, C.W. Brennan, D. Sym, E. Larson. The impact of personalized prenotification on response rates to an electronic survey. West J Nurs Res, 31 (1) (2009), pp. 17-23

[15] B.J. Kelly, T.K. Fraze, R.C. Hornik. Response rates to a mailed survey of a representative sample of cancer patients randomly drawn from the Pennsylvania Cancer Registry: a randomized trial of incentive and length effects. BMC Med Res Methodol, 10 (2010), p. 65 
[16] R. Slijkhuis, P. Terlouw, H.G. van der Kaap, R. van Zuidam, C. van Weert, D. Delnoij et al. Is Dillman absoluut? Onderzoek naar de invloeden van opmaak en contacttraject van de CQI vragenlijsten op de kwantitatieve respons, de kwalitatieve respons en de kosten van dataverzameling [Is Dillman final? Investigation into influences of questionnaire lay-out and sending scheme on qualitative and quantitative response and costs of data collection of CQI surveys] Universiteit Twente, Twente, The Netherlands (2008)

[17] D.M. Delnoij, G. ten Asbroek, O.A. Arah, J.S. de Koning, P. Stam, A. Poll et al. Made in the USA: the import of American Consumer Assessment of Health Plan Surveys (CAHPS) into the Dutch social insurance system. Eur J Public Health, 16 (6) (2006), pp. 652-659

[18] J.H. Stubbe, W. Brouwer, D.M. Delnoij. Patients' experiences with quality of hospital care: the Consumer Quality Index Cataract Questionnaire. BMC Ophthalmol, 7 (2007), p. 14

[19] J.H. Stubbe, T. Gelsema, D.M. Delnoij. The Consumer Quality Index Hip Knee Questionnaire measuring patients' experiences with quality of care after a total hip or knee arthroplasty. BMC Health Serv Res, 7 (2007), p. 60

[20] O.C. Damman, M. Hendriks, D.M.J. Delnoij, P. Spreeuwenberg. Ervaringen van verzekerden met de zorg en de zorgverzekeraars: Meting 2006 voor www.kiesBeter.nl [Experiences of insured with health care and health plans. Measurement 2006 for publication on www.kies-Beter.nl] NIVEL, Utrecht, The Netherlands (2006)

[21] D. de Boer, M. Hendriks, O.C. Damman, P. Spreeuwenberg, J. Rademakers. Ervaringen van verzekerden met de zorg en de zorgverzekeraars: CQ-index Zorg en Zorgverzekering, meting 2007 [Experiences of insured with health care and health plans. CQI health plan instrument, measurement 2007] NIVEL, Utrecht, The Netherlands (2007)

[22] C.G. Donselaar, D. de Boer, L. van der Hoek, J.C. Booij, J. Rademakers, M. Hendriks et al. Ervaringen van verzekerden met de zorg en de zorgverzekeraars. CQ-index zorg en zorgverzekering, meting 2010 [Experiences of insured with health care and health plans. CQI Health plan instrument, measurement 2009] NIVEL, Utrecht, The Netherlands (2010)

[23] M. Hendriks, D. Delnoij, S. van der Meulen-Arts, W. Brouwer, P. Spreeuwenberg. Ervaringen van verzekerden met de zorg en de zorgverzekeraars: consumenteninformatie voor www.kiesBeter.nl [Experiences of insured with health care and health plans. Consumer information published on www.kies-Beter.nl] NIVEL, Utrecht, The Netherlands (2005)

[24] M. Reitsma van Rooijen, D. de Boer, M. Hendriks, L. van der Hoek, J. Rademakers. Ervaringen van verzekerden met de zorg en de zorgverzekering. CQ-index zorg en zorgverzekering, meting 2008 [Experiences of insured with health care and health plans. CQI health plan instrument, measurement 2008] NIVEL, Utrecht, The Netherlands (2008)

[25] N. Zwijnenberg, M. Hendriks, D. de Boer, P. Spreeuwenberg, M. Zegers, J. Rademakers et al. Ervaringen van verzekerden met de zorg en zorgverzekeraars. CQ-index zorg en zorgverzekering, meting 2009 [Experiences of insured with health care and health plans. CQI Health plan instrument, measurement 2009] NIVEL, Utrecht, The Netherlands (2009)

[26] E. de Leeuw, M. Callegaro, J. Hox, E. Korendijk, G. Lensvelt-Mulders. The influence of advance letters on response in telephone surveys. Public Opin Q, 71 (2007), pp. 44134443

[27] H. Sixma, P. Spreeuwenberg, M. Zuidgeest, J. Rademakers. CQ-index ziekenhuisopname: meetinstrumentontwikkeling. Kwaliteit van de zorg tijdens ziekenhuisopnames vanuit het perspectief van de patient. De ontwikkeling van het meetinstrument, de psychometrische eigenschappen en het discriminerend vermogen [CQindex Hospital Admission: questionnaire development. Quality of care during hospital admissions from the patients' perspective. Development, psychometric testing test discriminative power questionnaire] NIVEL, Utrecht, The Netherlands (2009) [28] K. Uberla. Faktorenanalyse. Springer, Berlin, Heidelberg, New York (1971) 
Koopman, L., Donselaar, L.C.G., Rademakers, J.J., Hendriks, M. A prenotification letter increased initial response, whereas sender did not affect response rates. Journal of Clinical Epidemiology: 2013, 66(3), 340-348

BOX, FIGURES AND TABLES

What is new?

Key findings

- A prenotification letter does increase initial response speed.

What this adds to what was known?

- A combination of prenotification or a second reminder and varying sender of the cover letter in a patient survey had no additional effect on the response rates. Varying senders had no effect at all on response rates.

What is the implication and what should change now?

- A prenotification should be considered when quick response is desirable. More research is needed to investigate whether a more familiar sender might improve response rates. 
Table 1. Survey methods for the CQI health plan and the CQI hospital admission

\begin{tabular}{|c|c|c|c|c|c|}
\hline \multicolumn{4}{|l|}{ CQI health plan } & \multicolumn{2}{|c|}{ CQI hospital admission } \\
\hline Group 1 & Group 2 & Group 3 & Group 4 & Group A & Group B \\
\hline Research institute & Health insurance company & Research institute & Health insurance company & Health insurance company & Hospital \\
\hline \multicolumn{2}{|c|}{$\begin{array}{l}\text { Week 0: prenotification } \\
\text { Week 1: questionnaire with cover letter } \\
\text { Week 3: thank you/reminder postcard }\end{array}$} & \multicolumn{2}{|c|}{$\begin{array}{l}\text { Week 0: questionnaire with cover letter } \\
\text { Week 1: thank you/reminder postcard } \\
\text { Week 3: reminder with questionnaire }\end{array}$} & \multicolumn{2}{|c|}{$\begin{array}{l}\text { Week 0: questionnaire with cover letter } \\
\text { Week 1: thank you/reminder postcard } \\
\text { Week 4: reminder with questionnaire } \\
\text { Week 6: reminder }\end{array}$} \\
\hline
\end{tabular}

Abbreviation: CQI, consumer quality index. 
Table 2. Respondent characteristics CQI health plan

\begin{tabular}{|c|c|c|c|c|c|}
\hline Respondent characteristics & $\begin{array}{c}\text { Group } 1,{ }^{\mathrm{a}} n(\%), \\
\quad N=42\end{array}$ & $\begin{array}{c}\text { Group } 2,^{\text {a }} n(\%), \\
\quad N=50\end{array}$ & $\begin{array}{c}\text { Group } 3,^{\mathrm{a}} n(\%), \\
N=48\end{array}$ & $\begin{array}{c}\text { Group } 4,^{\mathrm{a}} n(\%), \\
\quad N=51\end{array}$ & $\begin{array}{c}\text { Total, } \boldsymbol{n}(\%), \\
\boldsymbol{N}=191\end{array}$ \\
\hline \multicolumn{6}{|c|}{ Age, yr $\left(\chi^{2}(21)=15.5352 ; P=0.80\right)$} \\
\hline $18-24$ & $1(2)$ & $2(4)$ & $3(6)$ & $1(2)$ & $7(4)$ \\
\hline $25-34$ & $5(12)$ & $2(4)$ & $3(6)$ & $5(10)$ & $15(8)$ \\
\hline $35-44$ & $6(14)$ & $14(28)$ & $5(10)$ & $7(14)$ & $32(17)$ \\
\hline $45-54$ & $8(19)$ & $7(14)$ & $10(21)$ & $11(22)$ & $36(19)$ \\
\hline $55-64$ & $11(26)$ & $11(22)$ & $11(23)$ & $12(24)$ & $45(24)$ \\
\hline $65-74$ & $5(12)$ & $10(20)$ & $11(23)$ & $9(18)$ & $35(18)$ \\
\hline$\geq 75$ & $6(14)$ & $3(6)$ & $4(8)$ & $6(12)$ & $19(10)$ \\
\hline Unknown & $0(0)$ & $1(2)$ & $1(2)$ & $0(0)$ & $2(1)$ \\
\hline \multicolumn{6}{|c|}{$\operatorname{Sex}\left(\chi^{2}(6)=4.2939 ; P=0.64\right)$} \\
\hline Male & $20(48)$ & $18(36)$ & $24(50)$ & $21(41)$ & $83(44)$ \\
\hline Female & $22(52)$ & $31(62)$ & $23(48)$ & $30(59)$ & $106(56)$ \\
\hline Unknown & $0(0)$ & $1(0)$ & $1(2)$ & $0(0)$ & $2(1)$ \\
\hline \multicolumn{6}{|c|}{ Health status $\left(\chi^{2}(15)=10.0564 ; P=0.82\right)$} \\
\hline Excellent & $5(12)$ & $3(6)$ & $6(13)$ & $5(10)$ & $19(10)$ \\
\hline Very good & $5(12)$ & $13(26)$ & 9 (19) & 7 (14) & $34(18)$ \\
\hline Good & $20(48)$ & $25(50)$ & $26(54)$ & $27(53)$ & $98(51)$ \\
\hline Moderate & $9(21)$ & $5(10)$ & $5(10)$ & $9(18)$ & $28(15)$ \\
\hline Bad & $2(5)$ & $3(6)$ & $2(4)$ & $3(6)$ & $10(5)$ \\
\hline Unknown & $1(2)$ & $1(2)$ & $0(0)$ & $0(0)$ & $2(1)$ \\
\hline \multicolumn{6}{|c|}{ Education $\left(\chi^{2}(12)=13.8079 ; P=0.31\right)$} \\
\hline Less then high school & $18(43)$ & $14(28)$ & $17(35)$ & $18(35)$ & $67(35)$ \\
\hline High school graduated & $15(36)$ & $22(44)$ & $17(35)$ & $25(49)$ & $79(41)$ \\
\hline College degree & $9(21)$ & $13(26)$ & $10(21)$ & $8(16)$ & $40(21)$ \\
\hline Different & $0(0)$ & $0(0)$ & $2(4)$ & $0(0)$ & $2(1)$ \\
\hline Unknown & $0(0)$ & $1(2)$ & $2(4)$ & $0(0)$ & $3(2)$ \\
\hline
\end{tabular}

Abbreviation: CQI, consumer quality index.

${ }^{\text {a }}$ Group 1 received a prenotification and a cover letter from a research institute, group 2 received a prenotification and a cover letter from a health insurance company, group 3 immediately received a questionnaire and a cover letter from a research institute, and group 4 immediately received a questionnaire and a cover letter from a health insurance company.

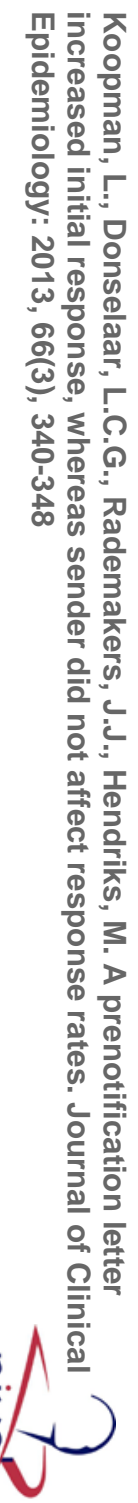


Table 3. Response speed in blocks of 7 days CQI health plan

\begin{tabular}{|c|c|c|c|c|c|}
\hline $\begin{array}{l}\text { Cumulative response after } \\
\text { sending a questionnaire (in days) }\end{array}$ & $\begin{array}{c}\text { Group } 1,{ }^{\mathrm{a}, \mathrm{b}} n(\%), \\
\quad N=151\end{array}$ & $\begin{array}{c}\text { Group } 2,{ }^{\mathrm{a}, \mathrm{b}} n(\%) \\
\quad N=166\end{array}$ & 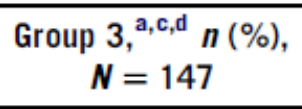 & $\begin{array}{c}\text { Group } 4,,^{\mathrm{a}, \mathrm{c}, \mathrm{d}} n(\%), \\
\boldsymbol{N}=163\end{array}$ & $\begin{array}{c}\text { Total, } n(\%), \\
N=627\end{array}$ \\
\hline$\overline{7}$ & $12(8)$ & $15(9)$ & $0(0)$ & $1(1)$ & $28(4)$ \\
\hline 14 & $22(15)$ & $23(14)$ & $26(18)$ & $34(21)$ & 105 (17) \\
\hline 21 & $26(17)$ & $35(21)$ & $31(21)$ & $42(26)$ & $134(21)$ \\
\hline 28 & $37(25)$ & $46(28)$ & $31(21)$ & $42(26)$ & $156(25)$ \\
\hline 35 & $37(25)$ & $46(28)$ & $43(29)$ & $49(30)$ & $175(28)$ \\
\hline 42 & $42(28)$ & $49(30)$ & $43(29)$ & $49(30)$ & $183(29)$ \\
\hline 49 & $42(28)$ & $49(30)$ & $48(33)$ & $50(31)$ & $189(30)$ \\
\hline Average response time & 17.2 & 15.9 & 21.6 & 17.1 & 18.0 \\
\hline
\end{tabular}

Abbreviation: $\mathrm{CQI}$, consumer quality index.

${ }^{a}$ Group 1 received a prenotification and a cover letter from a research institute, group 2 received a prenotification and a cover letter from a health insurance company, group 3 immediately received a questionnaire and a cover letter from a research institute, and group 4 immediately received a questionnaire and a cover letter from a health insurance company.

${ }^{\mathrm{b}}$ Group $1 / 2$ was sent a thank you note 14 days after sending the questionnaire.

${ }^{c}$ Group $3 / 4$ was sent a thank you note 7 days after sending the questionnaire.

d Group 3/4 was sent a reminder 21 days after sending the questionnaire. 
Table 2. Respondent characteristics CQI health plan

\begin{tabular}{|c|c|c|c|c|c|}
\hline Respondent characteristics & $\begin{array}{c}\text { Group } 1,{ }^{\mathrm{a}} n(\%), \\
\quad N=42\end{array}$ & $\begin{array}{c}\text { Group } 2,^{\text {a }} n(\%), \\
\quad N=50\end{array}$ & $\begin{array}{c}\text { Group } 3,^{\mathrm{a}} n(\%), \\
N=48\end{array}$ & $\begin{array}{c}\text { Group } 4,^{\mathrm{a}} n(\%), \\
\quad N=51\end{array}$ & $\begin{array}{c}\text { Total, } \boldsymbol{n}(\%), \\
\boldsymbol{N}=191\end{array}$ \\
\hline \multicolumn{6}{|c|}{ Age, yr $\left(\chi^{2}(21)=15.5352 ; P=0.80\right)$} \\
\hline $18-24$ & $1(2)$ & $2(4)$ & $3(6)$ & $1(2)$ & $7(4)$ \\
\hline $25-34$ & $5(12)$ & $2(4)$ & $3(6)$ & $5(10)$ & $15(8)$ \\
\hline $35-44$ & $6(14)$ & $14(28)$ & $5(10)$ & $7(14)$ & $32(17)$ \\
\hline $45-54$ & $8(19)$ & $7(14)$ & $10(21)$ & $11(22)$ & $36(19)$ \\
\hline $55-64$ & $11(26)$ & $11(22)$ & $11(23)$ & $12(24)$ & $45(24)$ \\
\hline $65-74$ & $5(12)$ & $10(20)$ & $11(23)$ & $9(18)$ & $35(18)$ \\
\hline$\geq 75$ & $6(14)$ & $3(6)$ & $4(8)$ & $6(12)$ & $19(10)$ \\
\hline Unknown & $0(0)$ & $1(2)$ & $1(2)$ & $0(0)$ & $2(1)$ \\
\hline \multicolumn{6}{|c|}{$\operatorname{Sex}\left(\chi^{2}(6)=4.2939 ; P=0.64\right)$} \\
\hline Male & $20(48)$ & $18(36)$ & $24(50)$ & $21(41)$ & $83(44)$ \\
\hline Female & $22(52)$ & $31(62)$ & $23(48)$ & $30(59)$ & $106(56)$ \\
\hline Unknown & $0(0)$ & $1(0)$ & $1(2)$ & $0(0)$ & $2(1)$ \\
\hline \multicolumn{6}{|c|}{ Health status $\left(\chi^{2}(15)=10.0564 ; P=0.82\right)$} \\
\hline Excellent & $5(12)$ & $3(6)$ & $6(13)$ & $5(10)$ & $19(10)$ \\
\hline Very good & $5(12)$ & $13(26)$ & 9 (19) & 7 (14) & $34(18)$ \\
\hline Good & $20(48)$ & $25(50)$ & $26(54)$ & $27(53)$ & $98(51)$ \\
\hline Moderate & $9(21)$ & $5(10)$ & $5(10)$ & $9(18)$ & $28(15)$ \\
\hline Bad & $2(5)$ & $3(6)$ & $2(4)$ & $3(6)$ & $10(5)$ \\
\hline Unknown & $1(2)$ & $1(2)$ & $0(0)$ & $0(0)$ & $2(1)$ \\
\hline \multicolumn{6}{|c|}{ Education $\left(\chi^{2}(12)=13.8079 ; P=0.31\right)$} \\
\hline Less then high school & $18(43)$ & $14(28)$ & $17(35)$ & $18(35)$ & $67(35)$ \\
\hline High school graduated & $15(36)$ & $22(44)$ & $17(35)$ & $25(49)$ & $79(41)$ \\
\hline College degree & $9(21)$ & $13(26)$ & $10(21)$ & $8(16)$ & $40(21)$ \\
\hline Different & $0(0)$ & $0(0)$ & $2(4)$ & $0(0)$ & $2(1)$ \\
\hline Unknown & $0(0)$ & $1(2)$ & $2(4)$ & $0(0)$ & $3(2)$ \\
\hline
\end{tabular}

Abbreviation: CQI, consumer quality index.

${ }^{\text {a }}$ Group 1 received a prenotification and a cover letter from a research institute, group 2 received a prenotification and a cover letter from a health insurance company, group 3 immediately received a questionnaire and a cover letter from a research institute, and group 4 immediately received a questionnaire and a cover letter from a health insurance company.

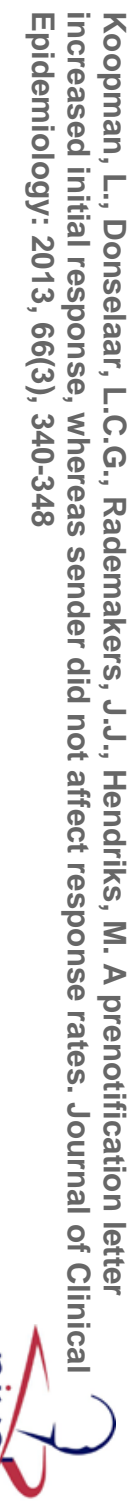


Table 3. Response speed in blocks of 7 days CQI health plan

\begin{tabular}{|c|c|c|c|c|c|}
\hline $\begin{array}{l}\text { Cumulative response after } \\
\text { sending a questionnaire (in days) }\end{array}$ & $\begin{array}{c}\text { Group } 1,{ }^{\mathrm{a}, \mathrm{b}} n(\%), \\
\quad N=151\end{array}$ & $\begin{array}{c}\text { Group } 2,{ }^{\mathrm{a}, \mathrm{b}} n(\%) \\
\quad N=166\end{array}$ & 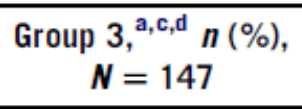 & $\begin{array}{c}\text { Group } 4,,^{\mathrm{a}, \mathrm{c}, \mathrm{d}} n(\%), \\
\boldsymbol{N}=163\end{array}$ & $\begin{array}{c}\text { Total, } n(\%), \\
N=627\end{array}$ \\
\hline$\overline{7}$ & $12(8)$ & $15(9)$ & $0(0)$ & $1(1)$ & $28(4)$ \\
\hline 14 & $22(15)$ & $23(14)$ & $26(18)$ & $34(21)$ & 105 (17) \\
\hline 21 & $26(17)$ & $35(21)$ & $31(21)$ & $42(26)$ & $134(21)$ \\
\hline 28 & $37(25)$ & $46(28)$ & $31(21)$ & $42(26)$ & $156(25)$ \\
\hline 35 & $37(25)$ & $46(28)$ & $43(29)$ & $49(30)$ & $175(28)$ \\
\hline 42 & $42(28)$ & $49(30)$ & $43(29)$ & $49(30)$ & $183(29)$ \\
\hline 49 & $42(28)$ & $49(30)$ & $48(33)$ & $50(31)$ & $189(30)$ \\
\hline Average response time & 17.2 & 15.9 & 21.6 & 17.1 & 18.0 \\
\hline
\end{tabular}

Abbreviation: $\mathrm{CQI}$, consumer quality index.

${ }^{a}$ Group 1 received a prenotification and a cover letter from a research institute, group 2 received a prenotification and a cover letter from a health insurance company, group 3 immediately received a questionnaire and a cover letter from a research institute, and group 4 immediately received a questionnaire and a cover letter from a health insurance company.

${ }^{\mathrm{b}}$ Group $1 / 2$ was sent a thank you note 14 days after sending the questionnaire.

${ }^{c}$ Group $3 / 4$ was sent a thank you note 7 days after sending the questionnaire.

d Group 3/4 was sent a reminder 21 days after sending the questionnaire. 
Koopman, L., Donselaar, L.C.G., Rademakers, J.J., Hendriks, M. A prenotification letter increased initial response, whereas sender did not affect response rates. Journal of Clinical Epidemiology: 2013, 66(3), 340-348

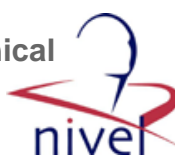

Fig. 1. Pattern of cumulative response speed in days CQI health plan: Prenotification vs. second reminder. P: prenotification groups 1 and 2; SR:

second reminder groups 3 and 4. 1: 7 Days after sending the questionnaire, SR groups received a thank you note; $2: 14$ days after sending the

questionnaire, $\mathrm{P}$ groups received a thank you note; and 3: 21 days after sending the questionnaire, SR groups received a second reminder.

CQI, consumer quality index.

\section{Cumulative response speed pattern}

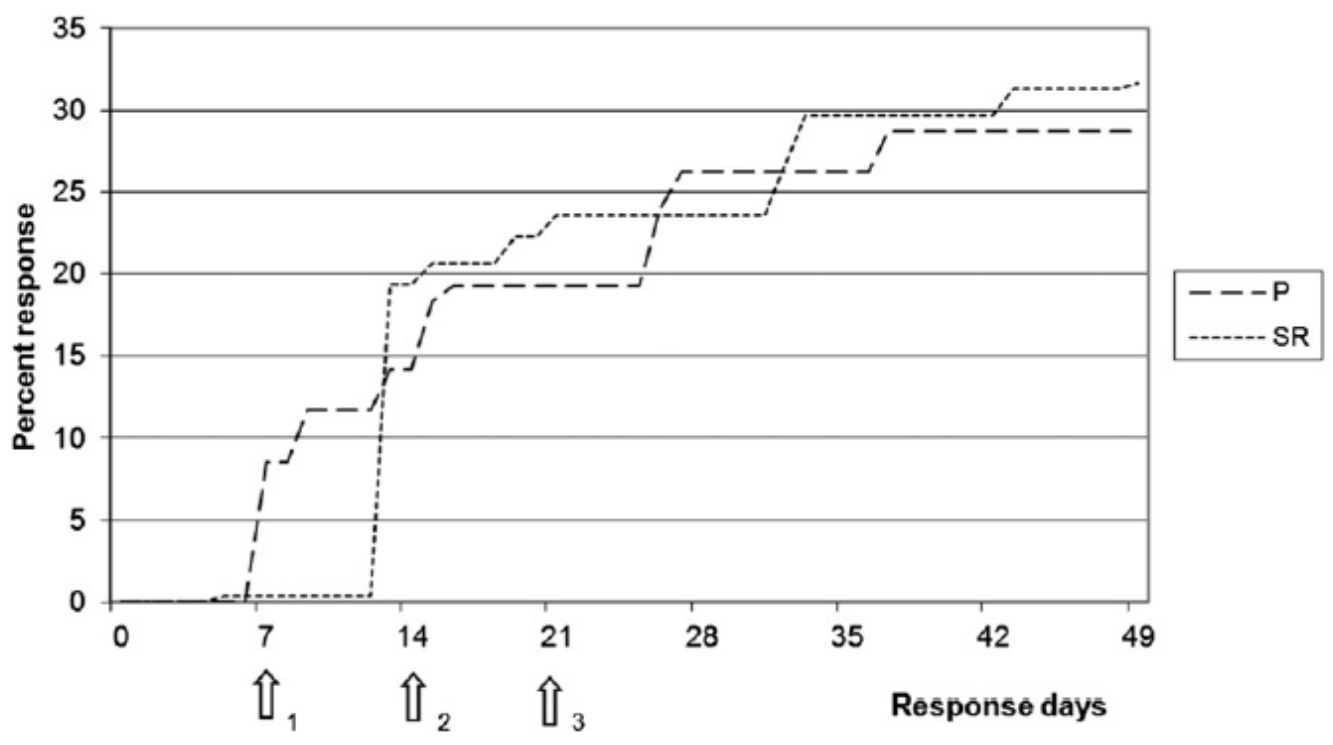

Fig. 2. Pattern of cumulative response speed in days CQI health plan: Research institute vs. health insurance company. RI: research institute group

1 and 3; HIC: health insurance company: group 2 and 4. CQI, consumer quality index.

\section{Cumulative response speed}

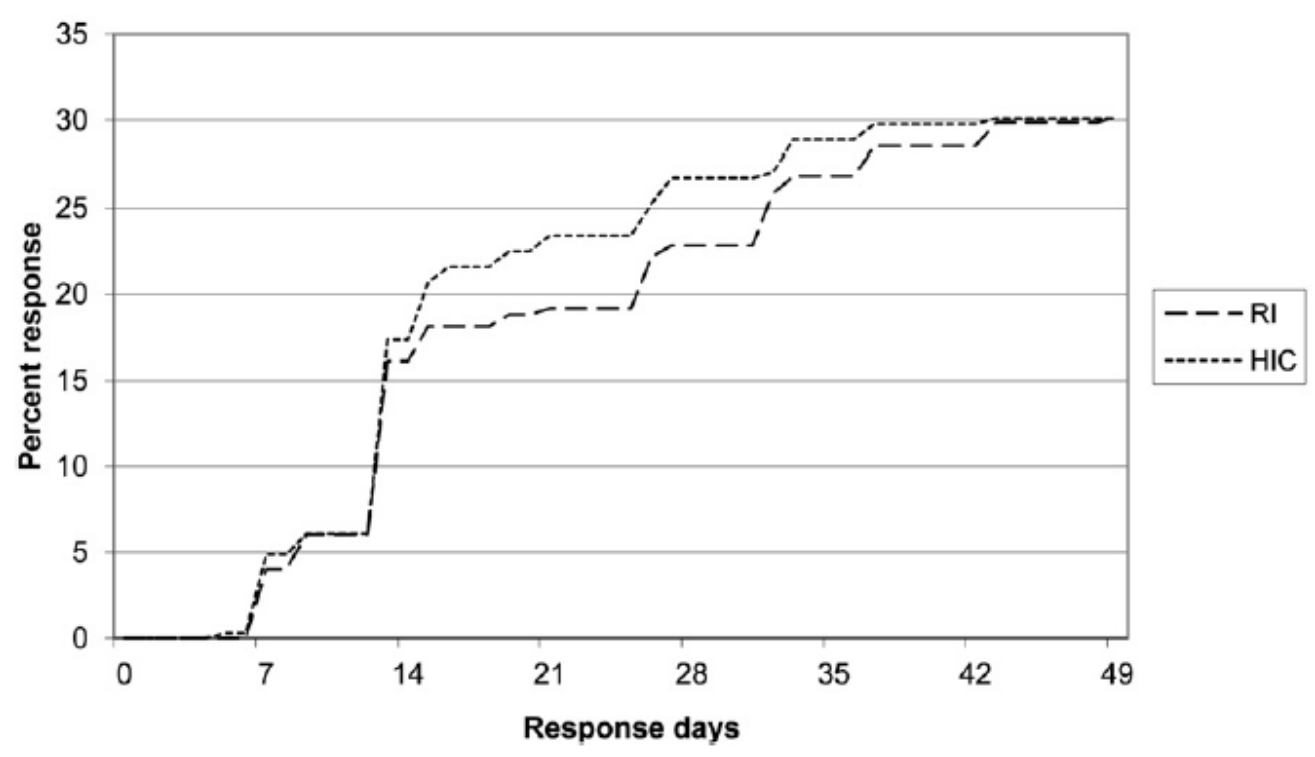


Koopman, L., Donselaar, L.C.G., Rademakers, J.J., Hendriks, M. A prenotification letter increased initial response, whereas sender did not affect response rates. Journal of Clinical Epidemiology: 2013, 66(3), 340-348

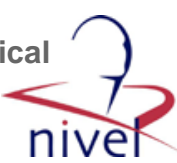

Table 4. Respondent characteristics CQI hospital admission

\begin{tabular}{|c|c|c|c|}
\hline $\begin{array}{l}\text { Respondent } \\
\text { characteristics }\end{array}$ & $\begin{array}{c}\text { Group A, } n(\%), \\
\quad N=54\end{array}$ & $\begin{array}{c}\text { Group B, } n(\%), \\
\quad N=56\end{array}$ & $\begin{array}{c}\text { Total, } \boldsymbol{n}(\%), \\
\boldsymbol{N}=110\end{array}$ \\
\hline \multicolumn{4}{|l|}{ Age, yr $(P=0.85)$} \\
\hline $18-24$ & $1(2)$ & $2(4)$ & $3(3)$ \\
\hline $25-34$ & $2(4)$ & $5(9)$ & $7(6)$ \\
\hline $35-44$ & $4(7)$ & $2(4)$ & $6(5)$ \\
\hline $45-54$ & $9(17)$ & $6(11)$ & $15(14)$ \\
\hline $55-64$ & 10 (19) & $13(23)$ & $23(21)$ \\
\hline $65-74$ & $13(24)$ & $14(25)$ & $27(25)$ \\
\hline$\geq 75$ & $14(26)$ & $13(23)$ & $27(25)$ \\
\hline Unknown & $1(2)$ & $1(2)$ & $2(2)$ \\
\hline \multicolumn{4}{|l|}{$\operatorname{Sex}(P=0.59)$} \\
\hline Male & $24(44)$ & $26(46)$ & $50(45)$ \\
\hline Female & $30(56)$ & $29(52)$ & $59(54)$ \\
\hline Unknown & $0(0)$ & $1(2)$ & $1(1)$ \\
\hline \multicolumn{4}{|c|}{ Health status $(P=0.98)$} \\
\hline Excellent & $5(9)$ & $4(7)$ & $9(8)$ \\
\hline Very good & $4(7)$ & $4(7)$ & $8(7)$ \\
\hline Good & $25(46)$ & $30(54)$ & $55(50)$ \\
\hline Moderate & $14(26)$ & $13(23)$ & $27(25)$ \\
\hline Bad & $5(9)$ & $4(7)$ & $9(8)$ \\
\hline Unknown & $1(2)$ & $1(2)$ & $2(2)$ \\
\hline \multicolumn{4}{|c|}{ Education $(P=0.76)$} \\
\hline $\begin{array}{l}\text { Less then high } \\
\text { school }\end{array}$ & $22(41)$ & $18(32)$ & $40(36)$ \\
\hline $\begin{array}{l}\text { High school } \\
\text { graduated }\end{array}$ & $24(44)$ & $27(48)$ & $51(46)$ \\
\hline College degree & $6(11)$ & $6(11)$ & $12(11)$ \\
\hline Different & $1(2)$ & $2(4)$ & $3(3)$ \\
\hline Unknown & $1(2)$ & $3(5)$ & $4(4)$ \\
\hline
\end{tabular}

Abbreviation: $\mathrm{CQI}$, consumer quality index.

Table 5. Response speed in blocks of 7 days CQI hospital admission

\begin{tabular}{lccc}
\hline $\begin{array}{l}\text { Cumulative response } \\
\text { after sending a } \\
\text { questionnaire (in days) }\end{array}$ & $\begin{array}{c}\text { Group A, } \\
\boldsymbol{n}(\%), \boldsymbol{N}=112\end{array}$ & $\begin{array}{c}\boldsymbol{n}(\%), \boldsymbol{N}=113 \\
\text { Group B, }\end{array}$ & $\begin{array}{c}\text { Total, } \boldsymbol{n}(\%), \\
\boldsymbol{N}=\mathbf{2 2 5}\end{array}$ \\
\hline 7 & $17(15)$ & $26(23)$ & $43(19)$ \\
14 & $17(15)$ & $27(24)$ & $44(20)$ \\
21 & $19(17)$ & $27(24)$ & $46(20)$ \\
28 & $19(17)$ & $27(24)$ & $46(20)$ \\
35 & $32(29)$ & $39(35)$ & $71(32)$ \\
42 & $48(43)$ & $46(41)$ & $94(42)$ \\
49 & $53(47)$ & $53(47)$ & $106(47)$ \\
56 & $54(48)$ & $55(49)$ & $109(48)$ \\
63 & $54(48)$ & $56(50)$ & $110(49)$ \\
Average response time & 28.1 & 23.7 & 25.9 \\
\hline
\end{tabular}

Abbreviation: CQI, consumer quality index.

After 7,28 , and 42 days, a reminder (thank you postcard or letter) was sent. 
Koopman, L., Donselaar, L.C.G., Rademakers, J.J., Hendriks, M. A prenotification letter increased initial response, whereas sender did not affect response rates. Journal of Clinical Epidemiology: 2013, 66(3), 340-348

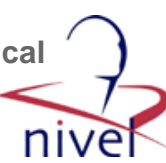

Fig. 3. Pattern of cumulative response speed in days CQI hospital admission. 1: 7 Days after sending the questionnaire, a thank you postcard was

sent; 2: 28 days after sending the questionnaire, a reminder letter was sent; 3: 42 days after sending the questionnaire, a reminder letter was sent.

CQI, consumer quality index.

Cumulative Response speed per day

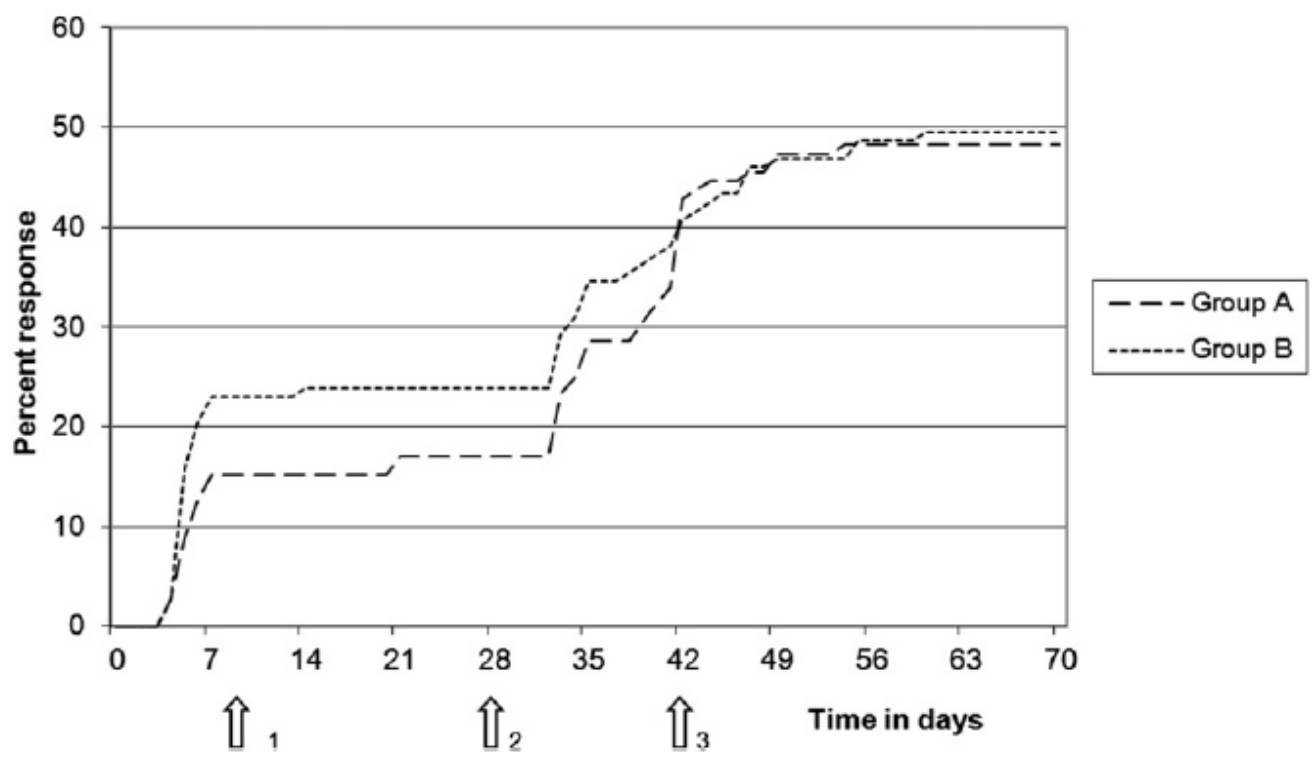

